\title{
Portable and Miniaturized Lab on a Chip with Regenerable Membrane for Sanitary Emergencies ${ }^{\dagger}$
}

\author{
Augusto Márquez *, Joan Aymerich, Pablo Giménez-Gómez, Michele Dei, \\ Francesc Serra-Graells, Cecilia Jiménez, Carlos Domínguez and Xavier Muñoz-Berbel \\ Institut de Microelectrònica de Barcelona, (IMB-CNM, CSIC, Esfera UAB), 08193 Bellaterra, Barcelona, Spain; \\ joan.aymerich@imb-cnm.csic.es (J.A.); pablo.gimenez@imb-cnm.csic.es (P.G.-G.); \\ michele.dei@imb-cnm.csic.es (M.D.); paco.serra@imb-cnm.csic.es (F.S.-G.); \\ cecilia.jimenez@imb-cnm.csic.es (C.J.); carlos.dominguez@imb-cnm.csic.es (C.D.); \\ xavier.munoz@imb-cnm.csic.es (X.M.-B.) \\ * Correspondence: augusto.marquez@imb-cnm.csic.es \\ + Presented at the 5th International Symposium on Sensor Science (I3S 2017), Barcelona, Spain, \\ 27-29 September 2017.
}

Published: 15 December 2017

A humanitarian crisis requires portable, integrated and versatile systems for fast and in situ analysis. Miniaturized and portable Lab on Chip (LoC) architectures integrating transduction, fluid management and signal processing are of interest in this field. In amperometric biosensors, biomolecules such as enzymes are used as a selective recognition element, which limits the application of the system to a single analyte. However, if this sensitive recognition part is refreshed with new and/or different recognition elements, reconfigurable devices are obtained, enabling ad lib selection of the analyte to be sensed. In the presented work, an electrodepositable alginate hydrogel is used to immobilize enzymes close to a microfabricated Pt transducer. After detection, the membrane is discarded and a new catalytic membrane can be electrodeposited on the same transducer. We demonstrated the possibility to sequentially quantify glucose and lactate with the same device without crosstalk and with no need for recalibration due to the repeatability of the electrodeposited membrane. This LoC also features signal digitalization and automatic measurement control enabled through a novel low-cost custom potentiostat architecture implemented with few standard dicrete electronic components presenting high versatility (from cycling voltammetries to chronoamperometries), high resolution (16 bits), simple connectivity (USB-OTG) and transducer cleaning capability.

(C) 2017 by the authors. Licensee MDPI, Basel, Switzerland. This article is an open access article distributed under the terms and conditions of the Creative Commons Attribution (CC BY) license (http://creativecommons.org/licenses/by/4.0/). 